\title{
Synthesis of $\mathbf{Y}$-hydroxypropyl P-chirogenic ( \pm )-phosphorus oxide derivatives by regioselective ring-opening of oxaphospholane 2-oxide precursors
}

\author{
Iris Binyamin, Shoval Meidan-Shani and Nissan Ashkenazi ${ }^{*}$
}

\author{
Full Research Paper \\ Address: \\ Department of Organic Chemistry, IIBR-Israel Institute for Biological \\ Research, P.O. Box 19, Ness Ziona, 74100, Israel

\section{Email:} \\ Nissan Ashkenazi - nissan.ashkenazi@iibr.gov.il \\ * Corresponding author \\ Keywords: \\ chirogenic phosphorus; Grignard reagents; oxaphospholanes; \\ phosphinates; phosphine oxides
}

\author{
Beilstein J. Org. Chem. 2015, 11, 1332-1339. \\ doi:10.3762/bjoc. 11.143 \\ Received: 02 March 2015 \\ Accepted: 16 July 2015 \\ Published: 30 July 2015 \\ Associate Editor: I. Marek \\ (C) 2015 Binyamin et al; licensee Beilstein-Institut. \\ License and terms: see end of document.
}

\begin{abstract}
The synthesis of P-chirogenic ( \pm )-phosphine oxides and phosphinates via selective nucleophilic ring opening of the corresponding oxaphospholanes is described. Two representative substrates: the phosphonate 2-ethoxy-1,2-oxaphospholane 2-oxide and the phosphinate 2-phenyl-1,2-oxaphospholane 2-oxide were reacted with various Grignard reagents to produce a single alkyl/aryl product. These products may possess further functionalities in addition to the phosphorus center such as the $\gamma$-hydroxypropyl group which results from the ring opening and $\pi$-donor moieties such as aryl, allyl, propargyl and allene which originates from the Grignard reagent.
\end{abstract}

\section{Introduction}

Organophosphorus compounds containing phosphorus to carbon bond(s) are widely used in organic transformations. Textbook examples are the Wittig and the Horner-Wadsworth-Emmons reactions. Moreover, the vast majority of ligands used in organometallic catalysis possess this bond(s). Among which organophosphorus compounds bearing three different alkyl (or aryl) ligands are of a great interest, as such compounds possess the essential backbone for P-chirogenic derivatives [1-3]. The formation of $\mathrm{P}-\mathrm{C}$ bonds [4-6] may be classified into two main types: (A) Attack by nucleophilic low valent phosphorus compounds (P(III) or phosphide ions $\mathrm{P}(\mathrm{II})$ ) on positively charged carbon centers (e.g., Michaelis-Arbuzov [7], Michaelis-Becker [8], Pudovik [9], Friedel-Crafts reactions [10], catalytic hydrophosphorylation [11] and others). Notably, these reactions commonly result in the formation of a pentavalent P-center which can no longer be exploited as a nucleophile. Therefore, this type of reaction can be used for the introduction of only one alkyl ligand. (B) Electrophilic P(V) compounds which can undergo a nucleophilic attack by various carbanions to form new $\mathrm{P}(\mathrm{V})$-carbon bond(s) [12]. While the 
former synthetic approach has been studied extensively and its scope and limitations are well documented, the full potential of the latter approach may be regarded as only partially exploited.

Similar to Grignard reactions with carboxylic esters, the formation of a $\mathrm{P}-\mathrm{C}$ bond from phosphate esters using these reagents, is limited [13]. The reactions are not selective and compounds containing multiple $\mathrm{P}-\mathrm{C}$ bonds are generally obtained [14]. In order to achieve better selectivity, a single alkyloxy substituent may be replaced by a halogen. This halogen will be substituted selectively under milder Grignard conditions to form a single $\mathrm{P}-\mathrm{C}$ bond, leaving the other ester groups intact $[15,16]$.

Cyclic phosphorus diesters are much more reactive towards nucleophilic reagents than their acyclic analogs. Specifically, 5-membered cyclic esters of phosphonic and phosphoric acids are known to undergo acid and alkaline hydrolysis at rates $10^{5}-10^{8}$ times faster than their acyclic analogs [17]. Thus, cyclic esters may be regarded as a halogen equivalent in terms of their leaving group ability under nucleophilic displacement conditions [18]. The rapid hydrolysis of 2-methoxy-1,3,2dioxaphospholane 2-oxide (1, Figure 1) exclusively forms a ring opening product [19-21]. This reaction proceeds via a trigonal bipyramidal (TBP) intermediate where the ring is constrained to span on apical and equatorial positions. Endocyclic cleavage of the phosphorus-oxygen bond at the apical position produces $\beta$-hydroxyethylphosphate (Scheme 1A). Dioxaphospholane 1 contains two identical oxygen atoms that can be cleaved with no preference due to fast pseudorotation between two practically energetically equivalent phosphorane intermediates, in which these two oxygen centers interconvert between apical to equatorial positions ( $a$ and b) [20]. Notably, some selectivity could be obtained once the $\mathrm{P}$ center of the phospholane is ligated to two different heteroatoms (i.e., $\mathrm{O}, \mathrm{N}$ or $\mathrm{O}, \mathrm{S}$ ) [22-27], albeit, both the $\mathrm{P}-\mathrm{O}$ and the $\mathrm{P}-\mathrm{N}$ bonds are susceptible to cleavage.

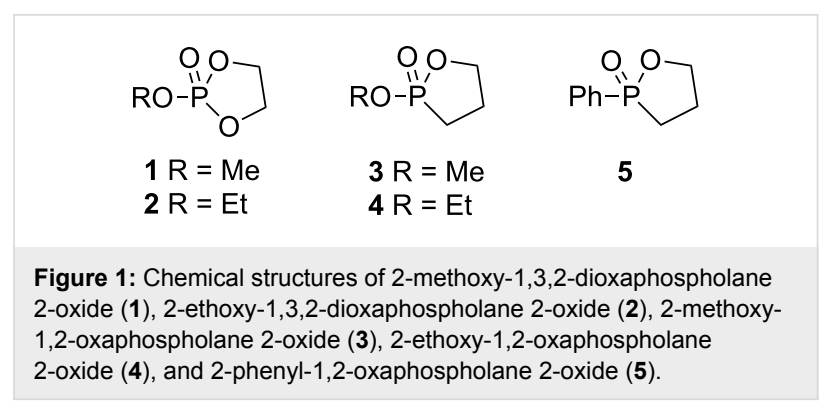

Kinetic studies of the ring openings of oxaphospholanes under acidic or alkaline conditions were also reported. 2-Methoxy1,2-oxaphospholane 2-oxide (3) [29] (Figure 1) undergoes a $\mathrm{P}-\mathrm{O}$ cleavage two orders of magnitude slower than the dioxaphospholane 1 [17], but at least three orders of magnitude faster than its acyclic analogs. Similarly, 2-phenyl-1,2-oxaphospholane 2-oxide (5) [30,31] (Figure 1) hydrolyzed under basic conditions 2 orders of magnitude slower than the dioxaphospholane analog, but $6.2 \times 10^{3}$ faster than the corresponding acyclic analog [32].

The ring opening of $\mathbf{3}$ and $\mathbf{5}$ under hydrolytic conditions was found to be completely regioselective [20], since the $\mathrm{P}-\mathrm{C}$ bond occupies the equatorial position according to the preference rules [33]. Therefore, fast pseudorotations (PR), either Berry's pseudorotation or Turnstile rotation [34], which form identical TBP intermediates, are suppressed (Scheme 1B). Thus, oxaphospholanes can potentially form a new $\mathrm{P}-\mathrm{C}$ bond in an entirely regioselective manner via cleavage of the single endocyclic $\mathrm{P}-\mathrm{O}$ bond [35-37]. Based on this mechanism, the unique properties of oxaphosphorinanes and oxaphospholanes may also be used to form chirogenic $( \pm)$-phosphorus compounds [26,38,39].

In our previous work, we investigated the reaction of 2-ethoxy1,3,2-dioxaphospholane 2-oxide (2) with Grignard reagents, and
(A)

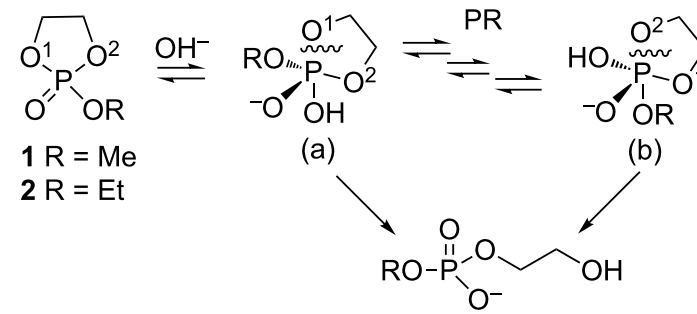

(c)
(B)

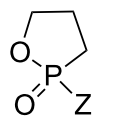

$4 Z=$ OEt

$5 \mathrm{Z}=\mathrm{Ph}$<smiles>[Z2][P+]1(O)(O)CCCO1</smiles>

(d)

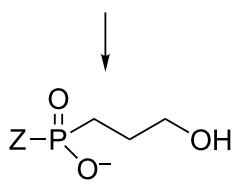

(e)

Scheme 1: (A) Alkaline hydrolysis of dioxaphospholane: the phosphorane intermediate includes one endocyclic oxygen atom at the apical position (a). Pseudorotation(s) may direct to a more stable TBP intermediate (b) [28]. Thus, the final product (c) can result from either $\mathrm{P}-\mathrm{O}^{1}$ or $\mathrm{P}-\mathrm{O}^{2}$ cleavage. (B) Alkaline hydrolysis of oxaphospholane: the most stable phosphorane intermediate in which the endocyclic oxygen atom is at the apical position (d) will not undergo pseudorotation(s) due to a high energetic barrier. The ring opening to the final product (e) is therefore regioselective. 
showed that phosphonates were formed as single products via a regioselective endocyclic $\mathrm{P}-\mathrm{O}$ bond cleavage [40-42]. In continuation of this work, we envisaged to expand this regioselective ring-opening strategy to oxaphospholane precursors in order to afford P-chirogenic $( \pm)$-phosphine oxide and phosphinate derivatives (Scheme 2).

Herein, we disclose our results on the reactions of oxaphospholanes 2-ethoxy-1,2-oxaphospholane 2-oxide (4) and 5 with various Grignard reagents. Indeed, in all cases, the attack on the phosphorus atom led exclusively to ring opening via endocyclic $\mathrm{P}-\mathrm{O}$ bond cleavage and formation of a new $\mathrm{P}-\mathrm{C}$ bond, yielding phosphinates and phosphine oxides with three different substituents on the phosphorus atom.

\section{Results and Discussion}

In order to establish that under Grignard conditions the selectivity between the endocyclic and the exocyclic $\mathrm{P}-\mathrm{O}$ bonds is not unique to $\mathbf{1}$ and $\mathbf{2}$, and that it is also retained in other oxaphospholanes, we first ran a series of reactions using the well-known oxaphospholane 4 [43] with various Grignard reagents such as aliphatic $(\mathrm{Me}, \mathrm{Et})$, aromatic $(\mathrm{Ph})$, cyclic (cyclopentyl) or allylic derivativess (Table 1). The products were identified by multinuclear NMR and MS (CI) detection.

Generally, the reaction was performed in cooled $\left(0^{\circ} \mathrm{C}\right)$ ether, using 3 equiv of the Grignard reagent, while warming to $\mathrm{rt}$ with stirring. The reaction time was determined using ${ }^{31} \mathrm{P}$ NMR monitoring, and we found that indeed, the attack of the Grignard reagents on the phosphorus atom of $\mathbf{4}$ led to an exclusive ring opening and the formation of the corresponding phosphinates within $0.5-1$ hour. We noticed that prolonged stirring at $\mathrm{rt}$ did not increase the conversion percentage to the desired products significantly. Under these reaction conditions $58-85 \%$ yield of $4 \mathbf{a}-\mathbf{e}$ were observed and the pure products were isolated in $30-80 \%$ yield following flash chromatography. The relative amount of the Grignard reagents used was found to be crucial as one equiv led to an incomplete reaction, while more than 3 equiv of the Grignard reagent led to dialkylation of the phosphorus atom, and formation of phosphine oxide side products. This phenomenon was most noticeable using phenylmagnesium bromide as a nucleophile: 2 equiv of the reagent were required to form $4 \mathrm{e}$ in $85 \%$ yield. The side product $5 \mathrm{e}$, which arises from side reaction of $\mathbf{4 e}$ with $\mathrm{PhMgBr}$ (Table 2), was obtained in $10 \%$ yield. In the case of the allyl compound, we increased the amount of allylmagnesium bromide up to 4 equivalents; however, the yield of $\mathbf{4 c}$ was limited to $58 \%$. The same trend was observed in our previous study once 2 was reacted with allylmagnesium chloride to form the respective allylphosphonate in considerably low yield [40-42].

The measured ${ }^{31} \mathrm{P}$ NMR chemical shifts of $\mathbf{4 a - d}$ appear at the characteristic region of 51-58 ppm, whereas for $4 \mathbf{e}$, which contains a highly electronegative benzene ring, the shift appears at $43 \mathrm{ppm}$. The ${ }^{13} \mathrm{C}$ NMR is most indicative for these systems. The signal of the propyl carbon in the $\alpha$-possition to the phosphorus atom in compounds $4 \mathbf{a}-\mathbf{e}$ was found to be at $\sim 25 \mathrm{ppm}$ with a doublet split pattern $\left(J_{\mathrm{P}-\mathrm{C}}\right.$ average of $\left.90 \mathrm{~Hz}\right)$. Another doublet with a similar $J_{\mathrm{P}-\mathrm{C}}$ coupling exist for the carbon of the $\mathrm{R}$ group. The chemical shift of this signal changes as a function of the R group character. The MS (CI) for all the phosphinates showed the $m / z[\mathrm{M}+1]$ signal.

It is well established that phosphinates can be readily converted into phosphine oxides at somewhat elevated temperatures $[44,45]$. Our hypothesis was that another possible attractive route to obtain phosphine oxides would be the reaction of aryl/ alkyl-oxaphospholanes with Grignard reagents. Oxaphospholane 5 was obtained according to Garner's procedure [43] using a one pot synthesis from two commercial starting materials, without isolation of intermediate 6 (Scheme 3). This method was found to be superior to two other protocols: reaction of phenyl disulfide with 3-hydroxypropyl(phenyl)phosphine oxide [30] and reaction of allyl alcohol with benzene phosphinic acid monobutyl ester in the presence of di-tert-butyl peroxide [46]. As both methods utilize phosphorus starting materials which are not commercially available and a multistep synthesis is required for their preparation.

As with oxaphospholane 4, compound 5 was reacted with 3 equiv of various Grignard reagents to produce phosphine oxides in high yields (83-97\%), leading after work-up and flash chromatography purification to high to moderate (38-95\%) isolated yields (Table 2). In general, the relatively higher yields of the phosphine oxides $\mathbf{5 a - 5 e}$ compared to the phosphinate analogs $\mathbf{4 a}-\mathbf{e}$ can be attributed to the lack of the exocyclic ester group in $\mathbf{5}$, which may be susceptible to a second alkylation/ arylation.

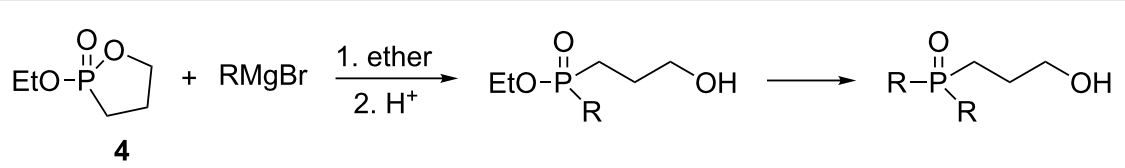


Table 1: Synthesis of $\mathrm{y}$-hydroxypropyl ( \pm )-phosphinates ${ }^{\mathrm{a}}$ and related compounds.

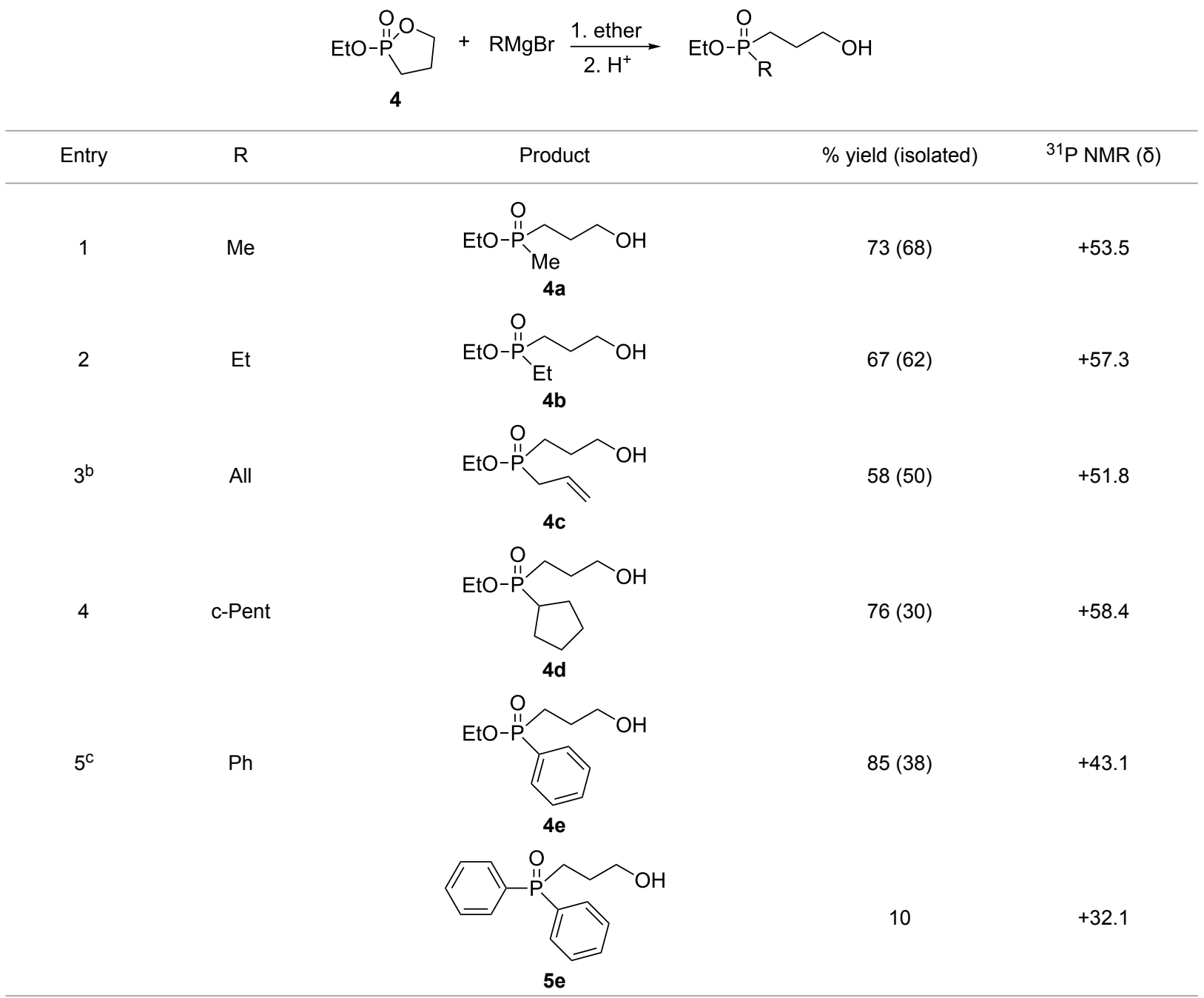

aReagents and conditions: $0.5 \mathrm{mmol}$ of 4 and $1.5 \mathrm{mmol}$ of the Grignard reagent were reacted in dry ether $(5 \mathrm{~mL})$ at $0{ }^{\circ} \mathrm{C}$, and stirred at rt for $0.5-1 \mathrm{~h}$. At the end of the reaction, the compound was hydrolyzed with $1.5 \mathrm{mmol} 1 \mathrm{~N} \mathrm{HCl} /$ ether. ${ }^{\text {b }} 4$ equiv of allylMgBr were used. ${ }^{\mathrm{c}} 2$ equiv of $\mathrm{PhMgBr}$ were used.

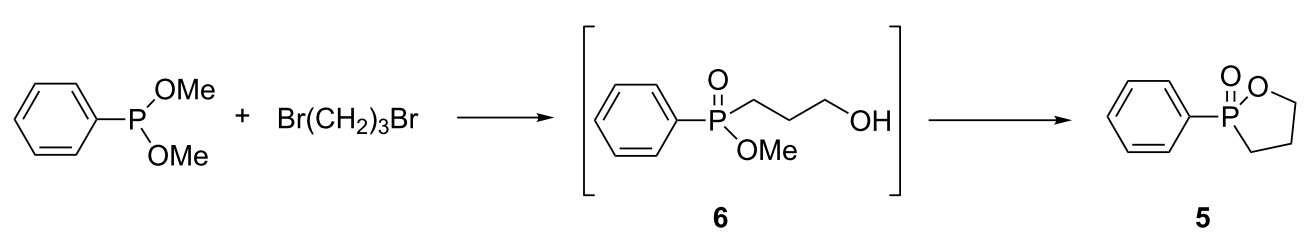

Scheme 3: Synthesis of 2-phenyl-1,2-oxaphospholane 2-oxide (5).

The ${ }^{31} \mathrm{P}$ NMR chemical shifts of $\mathbf{5 a}-\mathbf{d}$ appear at the characteristic $\sim+40$ ppm region. The respective signal for $\mathbf{5 e}$, which possess a second aryl substituent, appears in a higher field of $\delta$ $+32 \mathrm{ppm}$, as expected. Most indicative and informative are the ${ }^{13} \mathrm{C}$ NMR spectra. In comparison to the phosphinates, the
${ }^{13} \mathrm{C}$ NMR showed an average $J_{\mathrm{P}-\mathrm{C}}$ of $95 \mathrm{~Hz}$ for the phenyl quaternary carbon at $+132 \mathrm{ppm}$. The $J_{\mathrm{P}-\mathrm{C}}$ of the carbons were smaller than in the phosphinate system: $J_{\mathrm{P}-\mathrm{C}}$ of $65-73 \mathrm{~Hz}$ for the propyl carbon, and $J_{\mathrm{P}-\mathrm{C}}$ of $70 \mathrm{~Hz}$ for the R group (except for $\mathrm{R}=$ cyclopentyl, $J_{\mathrm{P}-\mathrm{C}}=40 \mathrm{~Hz}$ ). These results are in accordance 
Table 2: Synthesis of $y$-hydroxypropyl ( \pm )-phosphine oxides ${ }^{a}$.

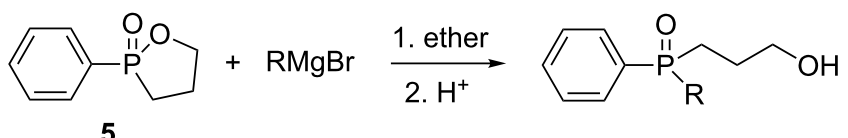

5

\begin{tabular}{|c|c|c|c|c|}
\hline Entry & $\mathrm{R}$ & (5) & $\%$ Yield (isolated) & ${ }^{31} \mathrm{P}$ NMR (ס) \\
\hline 1 & $\mathrm{Me}$ & $5 a$ & $90(77)$ & +37.5 \\
\hline 2 & Et & , & $83(79)$ & +41.9 \\
\hline $3^{b}$ & All & 5 & $87(71)$ & +37.1 \\
\hline 4 & c-Pent & $5 d$ & $91(62)$ & +42.8 \\
\hline 5 & $\mathrm{Ph}$ & $5 e$ & $97(95)$ & +32.2 \\
\hline
\end{tabular}

aReagents and conditions: $0.5 \mathrm{mmol}$ of 5 and $1.5 \mathrm{mmol}$ of the Grignard reagent were reacted in dry ether $(5 \mathrm{~mL})$ at $0{ }^{\circ} \mathrm{C}$, and stirred to rt for $1 \mathrm{~h}$. At the end of the reaction the compound was hydrolyzed with $1.5 \mathrm{mmol} 1 \mathrm{~N} \mathrm{HCl} /$ ether. $^{\mathrm{b}} 4$ equiv of allylMgBr were used.

to those of Simonnin et al. who showed that increasing the number of alkyl substituents on a phosphorus atom results in decrease of the $J_{\mathrm{P}-\mathrm{C}}$ values [47].

All these results indeed indicate that during the reactions a pentavalent TBP phosphorane intermediate is formed, which could not undergo pseudorotation due to a high energetic barrier. The endocyclic $\mathrm{P}-\mathrm{O}$ bond is cleaved almost exclusively (Scheme 4) to form the respective phosphinates and phosphine oxides in high yields.

Propargyl organophosphorus compounds present a unique interest from a synthetic point of view due to their ability to create new phosphines [48] or to be involved in various reactions (e.g., [2+3] cycloaddition) [49,50]. Moreover, propargyl compounds are known to undergo base catalyzed 1,3-prototropic rearrangments to the corresponding allenes [51], a highly usefull class of compounds [52-54]. Thus, we attempted to produce a propargylic analog by reacting 5 with propargylmagnesium bromide. The conditions required for this reaction were

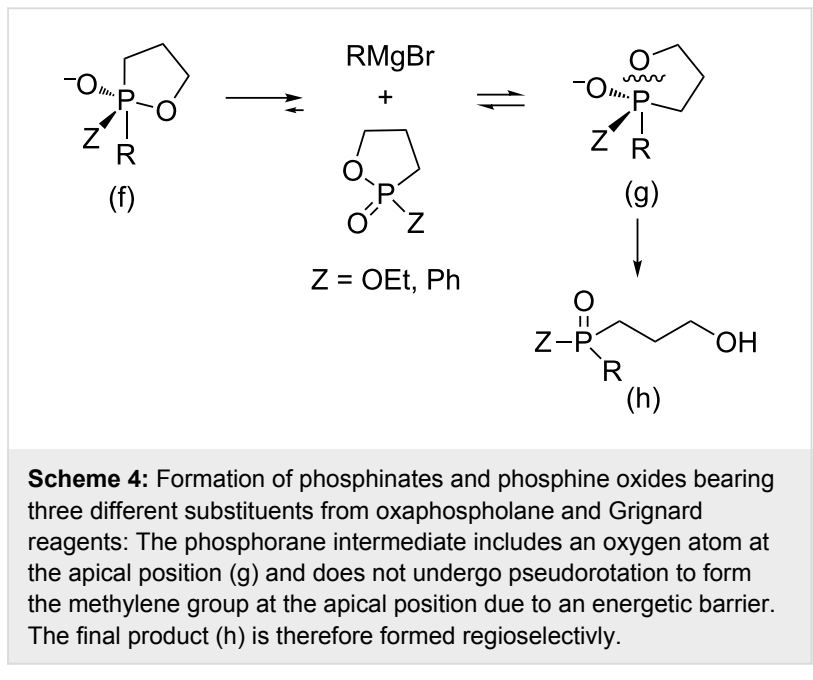

harsher than the previous ones: 5 equiv of the Grignard reagent and 5 were heated in THF for $18 \mathrm{~h}$. Further heating did not provide higher conversion. Following hydrolytic work-up and flash chromatographic purification the product was identified as 
allene $\mathbf{5 f}$, rather than acetylene $\mathbf{5 h}$, due to propargyl-allene rearrangement (Scheme 5). Most characteristic are the ${ }^{13} \mathrm{C}$ NMR chemical shift of $\mathrm{HC}=C=\mathrm{CR}$ at $213.36 \mathrm{ppm}$ and the ${ }^{1} \mathrm{H}$ NMR signals at $5.65 \mathrm{ppm}\left(\mathrm{dt}, J_{\mathrm{H} 1-\mathrm{H} 2}=6.9 \mathrm{~Hz}, J_{\mathrm{H} 1-\mathrm{P}}=\right.$ $2.7 \mathrm{~Hz})$ and $5.05 \mathrm{ppm}\left(\mathrm{dd}, J_{\mathrm{H} 2-\mathrm{P}}=10.8 \mathrm{~Hz}, J_{\mathrm{H} 2-\mathrm{H} 1}=6.9 \mathrm{~Hz}\right)$ which, together with the ${ }^{31} \mathrm{P}$ chemical shift at $+28.33 \mathrm{ppm}$, are in excellent agreement with the data reported in the literature for similar systems [55]. The expected mass (identical in the case of $\mathbf{5 f}$ and $\mathbf{5 h}$ ) was also obtained by MS (CI). Thus, it is likely to asume that the basic conditions favorize the deprotonation of a proton from the $\alpha$-possition to both the phosphoryl and the propargyl moieties, to afford the allenyl derivative by isomerization. Noteably, we cannot exclude the possibility that this rearrangement occurs already on the Grignard reagent and that the actual nucleophile is allenemagnesium bromide [56,57]. Nevertheless, it is reasonable to assume that prior to its acidic work-up $\mathbf{5 h}$ contains an intramolecular alkoxide function that may certainly serve as the catalytic base that prompts the rearrangment.
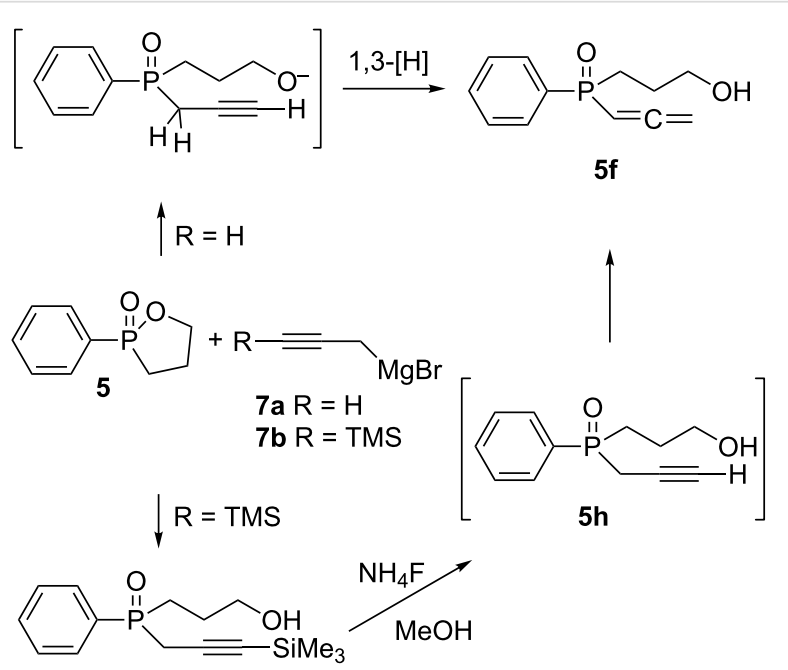

$5 \mathrm{~g}$

Scheme 5: Synthesis of acetylene and allene phosphine oxides.

The 1,3-hydrogen shift in a P-propargyl system is well established [51]. In an attempt to prevent this rearrangement we applied an acetylene substituted with the bulky TMS group [58], which may be easily removed at a later stage, and formed the 3-(trimethylsilyl)propargylmagnesium bromide (7b) [59]. The reaction of 5 with 5 equiv of $7 \mathbf{b}$ in THF for $48 \mathrm{~h}$ produced the protected propargylic analog $\mathbf{5 g}$ in $35 \%$ isolated yield. The ${ }^{31} \mathrm{P}$ NMR of this product exhibited a signal at $+35.6 \mathrm{ppm}$, and the ${ }^{13} \mathrm{C}$ NMR chemical shifts of the two acetylenic carbons were observed at $97.12 \mathrm{ppm}(\mathrm{d}, J=9.0 \mathrm{~Hz})$ and $89.80 \mathrm{ppm}(\mathrm{d}$, $J=7.5 \mathrm{~Hz}$ ). Attempts to cleave the TMS protecting group [60] of $\mathbf{5 g}$ led to the rearrangement product $\mathbf{5 f}$. Therefore, if a non- substituted porpargyl moiety is desired the TMS removal should be performed at a later stage of the synthesis (i.e., after the "click" reaction) [61].

\section{Conclusion}

In this work, we demonstrated the generality and the versatility of oxaphospholanes such as $\mathbf{4}$ and $\mathbf{5}$ to serve as precursors for the synthesis of $\gamma$-hydroxypropyl $( \pm$ )-phosphinates and phosphine oxides, respectively, using Grignard reactions. Noteworthy is the fact that the $\gamma$-hydroxypropyl substituent, which results directly from the ring opening of the phospholane, could provide a second ligation site upon complexation of the corresponding phosphines to a transition metal catalyst. These $\mathrm{P}, \mathrm{O}$ bidentate ligands are quite useful in organometallic compounds once binded to metals which favor a six-membered ring geometry. Moreover, these compounds could be advantageously used in organocatalysis and are commonly embedded in inorganic or organic matrix for various heterogeneous applications.

\section{Supporting Information}

\section{Supporting Information File 1}

Experimental details, characterization data and ${ }^{1} \mathrm{H}$ and

${ }^{13} \mathrm{C}$ NMR spectra of all new compounds.

[http://www.beilstein-journals.org/bjoc/content/ supplementary/1860-5397-11-143-S1.pdf]

\section{References}

1. Knowles, W. S. Angew. Chem., Int. Ed. 2002, 41, 1998-2007. doi:10.1002/1521-3773(20020617)41:12<1998::AID-ANIE1998>3.0.CO ;2-8

2. Kamer, P. C. J.; van Leeuwen, P. W. N. M., Eds. Phosphorus (III) Ligands in Homogeneous Catalysis: Design and Synthesis; John Wiley and Sons: Chichester, 2012.

3. Börner, A., Ed. Phosphorus Ligands in Asymmetric Catalysis Synthesis and Applications; Wiley-VCH: Weinheim, 2008.

4. Engel, R. Synthesis of Carbon-Phosphorus Bonds; CRC Press: Boca-Raton, FL, 1988.

5. Montchamp, J.-L. J. Organomet. Chem. 2005, 690, 2388-2406. doi:10.1016/j.jorganchem.2004.10.005

6. Jugé, S.; Malacea, R.; Tessier, A. Synthetically Derived Auxiliaries: Phosphorus Derivatives. In Synthetic Methods II- Chiral Auxiliaries, Boeckman, R., Ed.; Comprehensive Chirality; Elsevier: Oxford, 2012; pp 528-559.

7. Bhattacharya, A. K.; Thyagarajan, G. Chem. Rev. 1981, 81, 415-430. doi:10.1021/cr00044a004

8. Enders, D.; Saint-Dizier, A.; Lannou, M.-I.; Lenzen, A. Eur. J. Org. Chem. 2006, 29-49. doi:10.1002/ejoc.200500593

9. Cherkasov, R. A.; Galkin, V. I.; Khabibullina, A. B.; Kurdi, A. K. Phosphorus, Sulfur Silicon Relat. Elem. 1990, 49-50, 61-64. doi:10.1080/10426509008038907

10. Kosolapoff, G. M. Org. React. 1951, 6, 273-338.

11. Tanaka, M. Top. Curr. Chem. 2004, 232, 25-54. doi:10.1007/b13778 
12. Eymery, F.; lorga, B.; Savignac, P. Tetrahedron 1999, 55, 13109-13150. doi:10.1016/S0040-4020(99)00822-4

13. Engel, R. Formation of carbon-phosphorus bonds from phosphorus halide. Synthesis of Carbon-Phosphorus Bonds; CRC Press: Boca-Raton, FL, 1988; pp 165-194.

14. Berlin, K. D.; Peterson, M. E. J. Org. Chem. 1967, 32, 125-129. doi:10.1021/jo01277a032

15. Burger, A.; Dawson, N. D. J. Org. Chem. 1951, 16, 1250-1254. doi:10.1021/jo50002a010

16. Dawson, N. D.; Burger, A. J. Org. Chem. 1953, 18, 207-210. doi:10.1021/jo01130a012

17. Aksnes, G.; Bergesen, K. Acta Chem. Scand. 1966, 20, 2508-2514. doi:10.3891/acta.chem.scand.20-2508

18. Edmundson, R. S.; Wrigley, J. O. L. Tetrahedron 1967, 23, 283-290. doi:10.1016/S0040-4020(01)83312-3

19. Dennis, E. A.; Westheimer, F. H. J. Am. Chem. Soc. 1966, 88, 3432-3433. doi:10.1021/ja00966a046

20. Kluger, R.; Taylor, S. D. J. Am. Chem. Soc. 1991, 113, 5714-5719. doi:10.1021/ja00015a027

21. Taira, K.; Fanni, T.; Gorenstein, D. G. J. Org. Chem. 1984, 49, 4531-4536. doi:10.1021/jo00197a041

22. Hall, C. R.; Inch, T. D. Tetrahedron 1980, 36, 2059-2095. doi:10.1016/0040-4020(80)80096-2

23. Koizumi, T.; Yanada (nee Ishizaka), R.; Takagi, H.; Hirai, H.; Yoshii, E. Tetrahedron Lett. 1981, 22, 477-480. doi:10.1016/0040-4039(81)80130-X

24. Brown, J. M.; Laing, J. C. P. J. Organomet. Chem. 1997, 529, 435-444. doi:10.1016/S0022-328X(96)06660-0

25. Uziel, J.; Stephan, M.; Kaloun, E. B.; Genêt, J. P.; Juge, S. Bull. Soc. Chim. Fr. 1997, 134, 379-389.

26. Corey, E. J.; Chen, Z.; Tanoury, G. J. J. Am. Chem. Soc. 1993, 115, 11000-11001. doi:10.1021/ja00076a072

27. Vinci, D.; Mateus, N.; Wu, X.; Hancock, F.; Steiner, A.; Xiao, J. Org. Lett. 2006, 8, 215-218. doi:10.1021/ol0523704

28. Chang, N.; Lim, C. J. Am. Chem. Soc. 1998, 120, 2156-2167. doi:10.1021/ja9729802

29. Eberhard, A.; Westheimer, F. H. J. Am. Chem. Soc. 1965, 87, 253-260. doi:10.1021/ja01080a021

30. Grayson, M.; Farley, C. E. Chem. Commun. 1967, 830-831. doi:10.1039/c19670000830

31. Smith, C. R. Intermolecular Esters of Hydroxy or Amino Phosphonic Acid. U.S Patent 2,648,695, Aug 11, 1953.

32. Yang, J.-Y.; Gorenstein, D. G. Tetrahedron 1987, 43, 479-486. doi:10.1016/S0040-4020(01)89980-4

33. Gillespie, P.; Hoffman, P.; Klusacek, H.; Marquarding, D.; Pfohl, S.; Ramirez, F.; Tsolis, E. A.; Ugi, I. Angew. Chem., Int. Ed. Engl. 1971, 10, 687-715. doi:10.1002/anie.197106871

34. Ugi, I.; Marquarding, D.; Klusacek, H.; Gillespie, P.; Ramirez, F. Acc. Chem. Res. 1971, 4, 288-296. doi:10.1021/ar50044a004

35. Gorenstein, D. G.; Westheimer, F. H. J. Am. Chem. Soc. 1967, 89, 2762-2764. doi:10.1021/ja00987a062

36. Hall, C. R.; Inch, T. D. J. Chem. Soc., Perkin Trans. 1 1979, 1646-1655. doi:10.1039/p19790001646

37. Harrison, J. M.; Inch, T. D. J. Chem. Soc., Perkin Trans. 11979 , 2855-2862. doi:10.1039/p19790002855

38. Moffatt, J. G.; Khorana, H. G. J. Am. Chem. Soc. 1957, 79, 1194-1200. doi:10.1021/ja01562a044

39. Juge, S.; Genêt, J. P. Tetrahedron Lett. 1989, 30, 2783-2786. doi:10.1016/S0040-4039(00)99124-X
40. Ashkenazi, N.; Karton, Y.; Segall, Y. Tetrahedron Lett. 2004, 45 , 8003-8006. doi:10.1016/j.tetlet.2004.09.011

41. Ashkenazi, N.; Zade, S. S.; Segall, Y.; Karton, Y.; Bendikov, M. Chem. Commun. 2005, 5879-5881. doi:10.1039/b512117e

42. Ashkenazi, N.; Segall, Y.; Karton, Y.; Zade, S. S.; Bendikov, M. Phosphorus, Sulfur Silicon Relat. Elem. 2008, 183, 420-424. doi:10.1080/10426500701735452

43. Garner, A. Y. Phosphonic Acid Phostones. U.S. Patent 2,953,591, Sept 20, 1960.

44. Korpium, O.; Mislow, K. J. Am. Chem. Soc. 1967, 89, 4784-4786. doi:10.1021/ja00994a037

45. Korpium, O.; Lewis, R. A.; Chikos, J.; Mislow, K. J. Am. Chem. Soc. 1968, 90, 4842-4846. doi:10.1021/ja01020a017

46. Finke, M.; Kleiner, H.-J. Process for Preparing Cyclic Phosphinic Acid Esters. U.S. Patent 4,052,486, Oct 4, 1977.

47. Lequan, R.-M.; Pouet, M.-J.; Simonnin, M.-P. Org. Magn. Reson. 1975, 7, 392-400. doi:10.1002/mrc.1270070808

48. Kondoh, A.; Yorimitsu, H.; Oshima, K. Chem. - Asian J. 2010, 5 , 398-409. doi:10.1002/asia.200900447

49. Detz, R. J.; Heras, S. A.; de Gelder, R.; van Leeuwen, P. W. N. M.; Hiemstra, H.; Reek, J. N. H.; van Maarseveen, J. H. Org. Lett. 2006, 8, 3227-3230. doi:10.1021/ol061015q

50. Schuster, E. M.; Botoshansky, M.; Gandelman, M. Angew. Chem., Int. Ed. 2008, 47, 4555-4558. doi:10.1002/anie. 200800123

51. Hashmi, A. S. K. Synthesis of Allenes by Isomerization Reactions. In Modern Allene Chemistry; Krause, N.; Hashami, A. S. K., Eds.; Wiley-VCH Verlag GmbH: Weinheim, Germany, 2004. doi:10.1002/9783527619573.ch1

52. Sajna, K. V.; Kumara Swamy, K. C. J. Org. Chem. 2012, 77, 5345-5356. doi:10.1021/jo300705f

53. Phani Pavan, M.; Nagarjuna Reddy, M.; Bhuvan Kumar, N. N.; Kumara Swamy, K. C. Org. Biomol. Chem. 2012, 10, 8113-8118. doi:10.1039/c2ob26285a

54. Gangadhararao, G.; Kotikalapudi, R.; Nagarjuna Reddy, M.; Kumara Swamy, K. C. Beilstein J. Org. Chem. 2014, 10, 996-1005. doi:10.3762/bjoc. 10.99

55. Kalek, M.; Johansson, T.; Jezowska, M.; Stawinski, J. Org. Lett. 2010, 12, 4702-4704. doi:10.1021/ol102121j

56. Lappin, G. R. J. Am. Chem. Soc. 1949, 71, 3966-3968. doi:10.1021/ja01180a023

57. Chen, K.-H.; Feng, Y. J.; Ma, H.-W.; Lin, Y.-C.; Liu, Y.-H.; Kuo, T.-S. Organometallics 2010, 29, 6829-6836. doi:10.1021/om101017p

58. Agrawal, S.; Kataeva, O.; Schmidt, U.; Knölker, H.-J. RSC Adv. 2013, 3, 1089-1096. doi:10.1039/C2RA22823H

59. Vernekar, S. K. V.; Kipke, P.; Redlich, H. J. Carbohydr. Chem. 2008, 27, 10-31. doi:10.1080/07328300801991278

60. Schuster, E. M.; Nisnevich, G.; Botoshansky, M.; Gandelman, M. Organometallics 2009, 28, 5025-5031. doi:10.1021/om900545s

61. Preliminary reaction between $\mathbf{5 g}$ and azidomethyldiphenylphosphine oxide under "click" conditions as described in ref. [60] afforded the corresponding 1,2,3-triazole. These results will be reported elsewhere. 


\section{License and Terms}

This is an Open Access article under the terms of the Creative Commons Attribution License

(http://creativecommons.org/licenses/by/2.0), which permits unrestricted use, distribution, and reproduction in any medium, provided the original work is properly cited.

The license is subject to the Beilstein Journal of Organic Chemistry terms and conditions:

(http://www.beilstein-journals.org/bjoc)

The definitive version of this article is the electronic one which can be found at:

doi:10.3762/bjoc. 11.143 